\title{
Boosting health by improving air quality in the Western Balkans

V Matkovic Puljic ${ }^{1}$, M Jevtic ${ }^{2,3}$, S Kukolj ${ }^{1}$, C Bouland ${ }^{4}$

${ }^{1}$ Health and Environment Alliance, Brussels, Belgium

${ }^{2}$ Faculty of Medicine, University of Novi Sad, Novi Sad, Serbia

${ }^{3}$ ESP Research centre Environmental Health, Université Libre de Bruxelles, Brussels, Belgium

${ }^{4} \mathrm{RC}$ on Environmental and Occupational Health, School of Public Health, Université Libre de Bruxelles, Brussels, Belgium

Contact: vlatka@env-health.org

Implementing more stringent environmental rules in the Western Balkans is an opportunity to reduce the number of premature deaths and improve the health of people not only in the Western Balkan region but across Europe. Controlling air pollution from coal power plants is a huge opportunity to save 6,460 lives and 2,724 mil EUR in healthcare costs in the next decade.

As of 1st January 2018, the countries of the Western Balkans need to start reducing their emissions for large combustion plants and align national laws and rules with EU ones. This process is stemming from the Energy Community rules, which require coal plants currently operating in the Western Balkans to cut their emissions gradually from 2018 until the end of 2027.

The Western Balkans countries are home to the most polluting plants in the whole of Europe. Annual emissions from the 16 coal power plants in the Western Balkans are almost as high as from the 296 existing coal plants in the EU-28.

Coal power plants in the Western Balkans emit 13 times more $\mathrm{SO} 2$ and 30 times more PM2.5 per installed megawatt than the average European plant. Under the EU's Industrial Emissions Directive, emissions in the Western Balkans region would have to be reduced by $90 \%$ for SO 2 and by $67 \%$ of NOx and $94 \%$ of PM.

However, It is becoming increasingly clear that operators will struggle to keep the limit values for emissions already in 2018. The focus in 2018 should be on SO2 pollution control where most coal plants in the region should achieve underlines the current unpreparedness of coal power plants in the Western Balkans to meet emission standards.

In order to seize the huge health savings, Western Balkans governments need to start setting up pollution control measures in 2018. They should go for an ambitious path to reduce emissions, beyond what is required under the new rules. 